\title{
Effect of heating rate and plant species on the size and uniformity of silver nanoparticles synthesized using aromatic plant extracts
}

\author{
Jorge Luis Hernández-Pinero ${ }^{1,2} \cdot$ Manuel Terrón-Rebolledo ${ }^{1}$ Rahim Foroughbakhch ${ }^{1}$. \\ Sergio Moreno-Limón ${ }^{1}$ - M. F. Melendrez ${ }^{3}$ - Francisco Solís-Pomar ${ }^{4}$. \\ Eduardo Pérez-Tijerina ${ }^{4}$
}

Received: 9 March 2016/Accepted: 28 April 2016/Published online: 24 May 2016

(C) The Author(s) 2016. This article is published with open access at Springerlink.com

\begin{abstract}
Mixing aqueous silver solutions with aqueous leaf aromatic plant extracts from basil, mint, marjoram and peppermint resulted in the synthesis of quasi-spherical silver nanoparticles in a range of size between 2 and $80 \mathrm{~nm}$ in diameter as analyzed by analytical high-resolution electron microscopy. The average size could be controlled by applying heat to the initial reaction system at different rates of heating, and by the specific botanical species employed for the reaction. Increasing the rate of heating resulted in a statistically significant decrease in the size of the nanoparticles produced, regardless of the species employed. This fact was more evident in the case of marjoram, which decreased the average diameter from $27 \mathrm{~nm}$ at a slow rate of heating to $8 \mathrm{~nm}$ at a high rate of heating. With regard to the species, minimum sizes of
\end{abstract}

Jorge Luis Hernández-Pinero

jorge.hernandezpe@uanl.edu.mx

$\bowtie$ Francisco Solís-Pomar

francisco.solispm@uanl.edu.mx

1 Facultad de Ciencias Biológicas, Universidad Autónoma de Nuevo León, Av. Universidad s/n, 66455

San Nicolás De Los Garza, N.L., Mexico

2 Centro de Innovación Investigación y Desarrollo en Ingeniería y Tecnología (CIIDIT), PIIT Monterrey, Km. 10 carretera internacional de Monterrey, 66600 Apodaca, N.L., Mexico

3 Advanced Nanocomposites Research Group (GINA), Hybrid Materials Laboratory (HML), Department of Materials Engineering (DIMAT), Faculty of Engineering, University of Concepcion, 270 Edmundo Larenas, Box 160-C, 4070409 Concepcion, Chile

4 Facultad de Ciencias Físicas y Matemáticas, Universidad Autónoma de Nuevo León, Av. Universidad s/n, 66455 San Nicolás De Los Garza, N.L., Mexico
$<10 \mathrm{~nm}$ were obtained with basil and peppermint, while marjoram and mint yielded an average size between 10 and $25 \mathrm{~nm}$. The results indicate that aromatic plant extracts can be used to achieve the controlled synthesis of metal nanoparticles.

Keywords Silver nanoparticles · Synthesis - Green chemistry $\cdot$ Nanotechnology $\cdot$ Plant extracts $\cdot$ Heating rate

\section{Introduction}

It is now recognized that nanotechnology has potential applications in diverse fields such as electronics, medicine and other disciplines, due to the unique physical and chemical properties of nanostructured materials (Glomm 2005; Chan 2006; Boisselier and Astruc 2009). Structures that are now routinely synthesized in academic and industrial laboratories include nanotubes, nanoprisms, nanowires and nanoparticles as important constituents in nanoscale technological systems and devices. The geometry, composition, and average size are key determinants in the properties of the resulting nanostructures, i.e., the inhibitory effect of silver nanoparticles (AgNPs) in the growth of bacteria (Sukdeb et al. 2007). Thus, one of the fundamental aspects in the development of nanotechnology is to control the synthesis of these basic structural units. Metal nanoparticles are generally made up of atomic aggregations that grow as spherical or quasi-spherical structures with dimensions between 1 and $100 \mathrm{~nm}$ in diameter. Various physical and chemical methods of nanoparticle synthesis have been developed in recent history. However, despite improvements in the efficiency of synthetic methods to increase the amounts and quality of the nanoparticles produced, these methods largely still 
require highly toxic and expensive chemicals that generate a large amount of products harmful to human health, and that may cause considerable ecological risk if released into the environment as industrial waste.

A developing area in nanotechnology is the field of nanobiotechnology, which combines the principles of biology, physics, and chemistry to generate nanostructured materials with specific properties (Ahmad et al. 2003). Nanobiotechnology describes the application of biological systems for the production and functionalization of new materials, including nanoparticles (Zygmunt 2010). This definition encompasses a green chemistry approach aimed at the design, development and implementation of chemical products and processes to reduce or eliminate the use and generation of substances hazardous to human health and the environment. It is based on several principles that are summarized as: the prevention of waste generation, designing synthetic processes that incorporate all reagents, minimizing the chemical synthesis of dangerous and toxic products, energy economy, use of renewable raw materials, reduction of byproducts, use of catalysts, and obtaining degradable products in a clean and safe manner (Anastas et al. 1998). For this purpose, the list of traditional methods employed in the synthesis of metal nanoparticles may now include biological processes using whole living organisms, parts of them or their extracts thereof. The latter may be obtained from fresh plants containing elaborate biochemical components that have the ability to reduce electrolyte elements to metallic nanostructured arrays. Gardea et al. (2003) were the first to observe AgNPs in living plant tissues after root absorption of $\mathrm{Ag}^{+}$from a substrate rich in the metal. Those findings suggest that certain plants have the biochemical machinery to reduce cations to their metallic forms. Since then, several authors have reported the use of plant extracts as reduction media for the synthesis of AgNPs in most of the families of the kingdom Plantae (see reviews Iravani 2011; Narayanan and Sakthivel 2011; Gan and Li 2012; Mittal et al. 2013.

Although there has lately been an overwhelming amount of evidence regarding the capability of plants from many groups and unrelated botanical families to reduce silver and other metals to their metallic forms, a major limitation in their use is the control of key nanoparticle parameters such as uniformity in size. Researchers have very recently discovered a new way of synthesizing metallic nanoparticles that overcomes weaknesses such as low stability. Suresh et al. (2011) recently added $\mathrm{Cu}$ nanoparticles to $\mathrm{Al}_{2} \mathrm{O}_{3}$ nanoparticles and synthesized the mixture through a twostep thermomechanical method. The stability of the mixture was improved by adding alumina, a ceramic material, to the metallic copper nanoparticles. Following their work, Takabi and Salehi (2014) and Takabi and Shokouhmand
(2015) showed that the thermal efficiency of this mixture is higher than that of the metallic nanoparticles alone.

In this investigation, we employed herbal species whose extracts contain high concentrations of aromatic molecules to achieve the large scale synthesis of AgNPs with improved quality and reduced capital costs. This method adheres to the principles of green chemistry and enhances available data on the processes involved in the bioreduction of metals. Varying the kinetics of the synthesis reaction by heat had a marked effect on the average size, and resulted in a more even size distribution of the AgNPs.

\section{Experimental section}

\section{Biological material}

Fresh leaves of Ocimum basilicum L. (basil), Origanum majorana L. (marjoram), Satureja mexicana Briq. (mint), and Mentha piperita L. (peppermint) were obtained commercially from local markets. Identification of the species was carried out with taxonomical keys (Bailey 1949; Epling and Játiva 1966). Plant extracts were obtained by homogenizing $10 \mathrm{~g}$ of previously washed and dried leaves in $200 \mathrm{~mL}$ of distilled water, and boiling the mixture for $1 \mathrm{~min}$. The extracts were vacuum filtered with Whatman No. 41 paper, and refrigerated until use.

\section{Synthesis of silver nanoparticles}

For each species, a 1:9 mixture of foliar aqueous extract and $10^{-3} \mathrm{M}$ silver nitrate solution was prepared at room temperature, having a final volume of $100 \mathrm{~mL}$. To determine the effect of heating on the nanoparticle morphology, the resulting mixtures were heated with constant agitation up to $90{ }^{\circ} \mathrm{C}$ on a heating plate at three different average rates of heating: (1) $4{ }^{\circ} \mathrm{C} / \mathrm{min}$, (2) $13{ }^{\circ} \mathrm{C} / \mathrm{min}$, and (3) $42{ }^{\circ} \mathrm{C} / \mathrm{min}$. The corresponding times to reach $90{ }^{\circ} \mathrm{C}$, from a starting temperature of $25^{\circ} \mathrm{C}$, were (1) $15 \mathrm{~min}$, (2) $5 \mathrm{~min}$, and (3) $1.5 \mathrm{~min}$, respectively. The final temperature was maintained throughout the reaction time of $60-80 \mathrm{~min}$. The conversion of $\mathrm{Ag}^{+}$to $\mathrm{Ag}^{0}$ was monitored during the synthesis by observing color changes in the solutions and measuring their surface plasmon resonance with an UVVis Beckman DV640 spectrophotometer.

The kinetics of each reaction at these different rates of temperature increase were obtained by plotting the maximum value of absorbance against the time of the reaction at that point for every species and treatment. Thus, the surface plasmon resonance was measured every $10 \mathrm{~min}$. The maximum absorbance value was obtained from the resulting peak near $420 \mathrm{~nm}$, the typical value for spherical AgNPs. 


\section{Nanoparticle morphometry}

The resulting nanoparticle suspension was analyzed on carbon-coated copper grids in a high-resolution transmission electron microscope (FEI Titan G2 80 300) operating at an accelerating voltage of $300 \mathrm{kV}$ in TEM mode. The acquired digital images were analyzed with a Gatan Digital Micrograph software system to determine their shape and size distribution. To confirm their metallic silver composition, samples were also observed in a scanning electron microscope (FEI Nova NanoSEM 200 ) with an EDAX elemental analysis system. Statistical analysis by simple ANOVA and Tukey multiple mean comparisons (Zar 2010) of the obtained size data was carried out with SPSS software version 17 , while graphic representations were made with Origin Pro 8 software.

To obtain the size distribution of nanoparticles, five micrographs were taken at random fields of observation in each sample. The nanoparticle diameters were measured starting in the first micrograph until $100 \mathrm{U}$ was completed, which usually occurred in the fourth or fifth micrograph.

\section{Results and discussion}

Throughout the evolutionary history of plants, a great quantity of vegetal metabolites have originated as an adaptive response to continuous changes that have occurred in the environment which, in part, allowed them to colonize all types of biomes. Some of these metabolites play vital specific functions such as carriers, precursors in physiological processes (like cell respiration and photosynthesis), growth regulating hormones, reproductive cycles, and many others. A number of reactive compounds may be also derived from the cell catabolic and anabolic processes, which could generate an oxidative chemical environment favored in turn by the presence of oxygen (Triantaphylide and Havaux 2009; Glasauer and Chandel 2013). These reactive oxygen species may build up as a response to various types of stress and eventually promote cellular aging.

To counteract the oxidative damage and aberrant cell signaling resulting in pathologies caused by the accumulation of these compounds in the cell, plants have developed a number of chemical antioxidant systems to buffer their concentration below optimum levels so that the normal cell physiological functioning is not altered. In this way, some plant species living under certain stress, including high levels of heavy metals, have generated adaptive responses to reduce the oxidative potential. These include the biosynthesis of phytochelatins (organic molecules with properties that make them capable of reducing metals), antioxidant enzymes (superoxide dismutase, catalase and glutathione peroxidase), reducing sugars, flavonoids, terpenoids and organic acids (such as malate, citrate, oxalate). Some of these compounds are generally regarded as potential bioreducing and stabilizing agents that could render the formation of AgNPs through the interactions between these components in the biomass and ionic silver (Gan and $\mathrm{Li}$ 2012).

The botanical species selected in this research have in common a high content of antioxidants and phenolic compounds with essential properties such as flavonoids, terpenoids (carotenoids and xanthophylls), chlorophyll and ascorbic acid (Lee et al. 2005; Vági et al. 2005; Lubbe and Verpoorte 2011). These compounds can be extracted from the cell via the liquefaction of plant tissues to obtain a homogeneous vegetal extract rich in biochemical compounds. The extract is a reaction medium with a high reducing potential, which is of special interest for this work because it allows the reduction of ionic silver to metallic silver, boosting the formation of precursor growth nuclei from which the nanoparticles are formed.

In this work, synthesis of AgNPs occurred during the reaction of the $10^{-3} \mathrm{M}$ silver nitrate solution with the aqueous leaf plant extracts. This was confirmed by the visual observation of changes in the color of the emulsion, from almost transparent to a brownish tint. These color changes occurred more rapidly when heating was applied. Actual synthesis of the AgNPs was further confirmed by electron microscopy. The plasmon resonance curves obtained by spectrophotometry of the reaction solution showed a rapid increase in the typical silver surface plasmon resonance, with a peak close to the $420-\mathrm{nm}$ wavelength which is characteristic of spherical AgNPs. Growth of the peak occurred concomitantly with the reaction kinetics for the four treated species (Figs. 1, 2, 3, 4a, b). However, a slight shift of the curves to the right side of the graph at longer times suggests a small change in the average size or geometry of the nanoparticles in the colloid emulsion after long periods of heating.

The reactions of the ionic silver with the components of the vegetal extracts were all carried out at $90{ }^{\circ} \mathrm{C}$. Three rates of heating were applied, starting from room temperature, to identify how the heating rate affects the size of the resulting nanoparticles. The kinetics of each reaction at these different rates of temperature increase showed that saturation occurred more rapidly at a higher rate of heating, so that no further increase in absorbance was observed at the highest heating rate after $15 \mathrm{~min}$, for any species, but times around $60 \mathrm{~min}$ were necessary at the slowest rate of heating (Figs. 1, 2, 3, 4b). A variety of investigations on the synthesis of AgNPs have been done at fixed reaction temperatures, which have disclosed the importance of this parameter to characteristics such as the size and shape of the final product (Fayaz et al. 2009; Jiang et al. 2011). 
Fig. 1 Origanum majorana (marjoram). a Vis absorption spectra during the reaction time of $10^{-3} \mathrm{M} \mathrm{AgNO}_{3}$ with the plant extract. b Reaction kinetics at different initial heating rates. c Size distribution of the synthesized AgNPs. d AgNP average size after different initial heating rates. e, f TEM micrographs
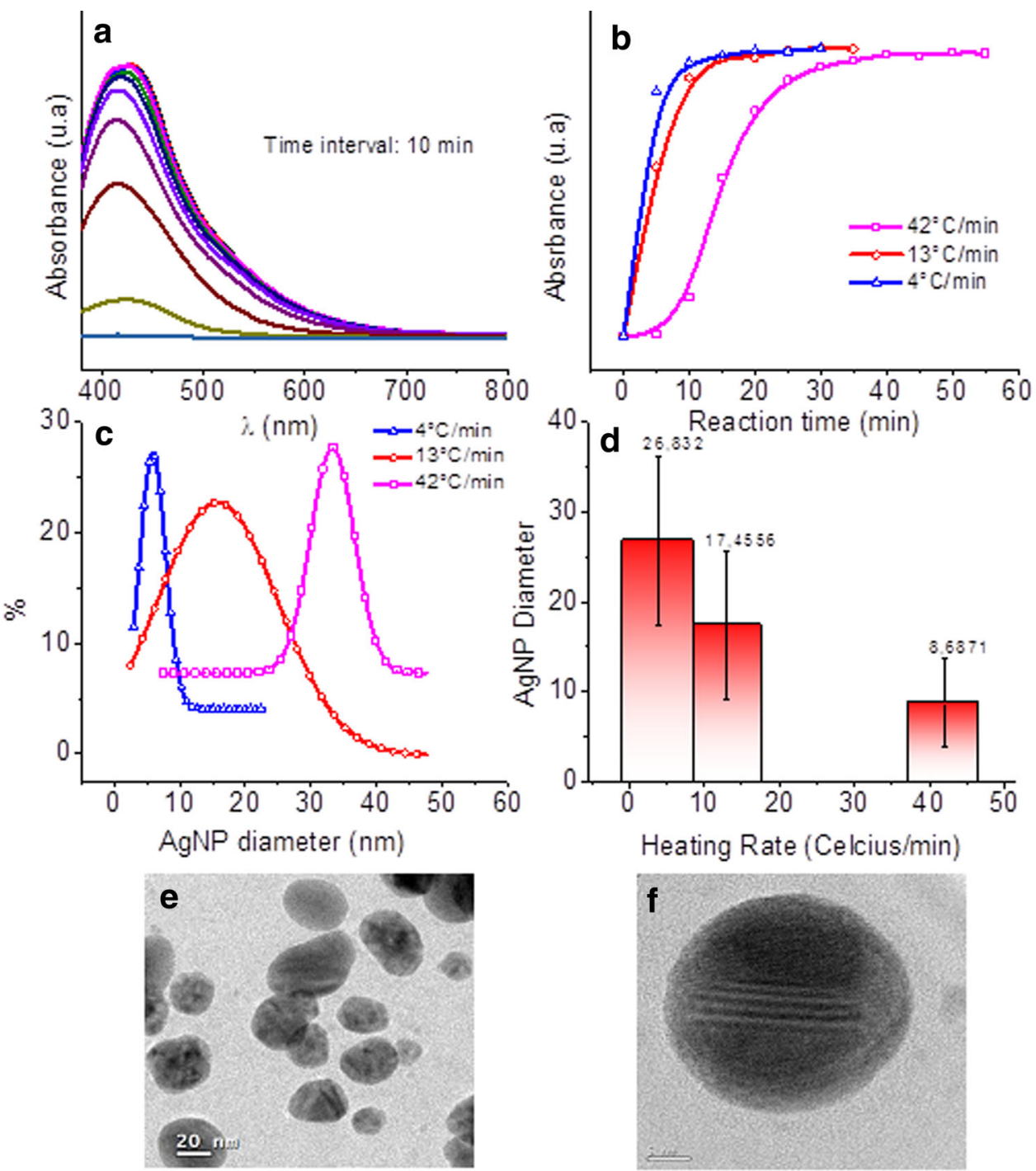

At each heating rate, for each species, the synthesis of nanoparticles was demonstrated by electron microscopy of the resulting homogenized emulsions after the end of the reaction. For the counting and characterization of the AgNPs, the TEM images were obtained at low and high magnification and resolution. The former showed a spherical or quasi-spherical geometry for most of the nanoparticles, and the latter showed their crystalline atomic configuration characteristic of metals (Figs. 1, 2, 3, 4e, f). The silver composition of the nanoparticles was demonstrated by EDX analysis of air desiccated samples under the scanning electron microscope. Figure 5 shows an example of the EDX spectrum obtained in the SEM from a mixture of silver nitrate with the leaf extract of $M$. piperita, where the signal peaks from silver and other plant elements are evident. The silver X-ray counts were similarly high in all other species (not shown).
The average size of the round nanoparticles was determined as a function of their diameters, as measured by TEM. These results varied depending on the species and the heating rate applied. AgNPs with $<2 \mathrm{~nm}$ in diameter could be observed, as well as large nanoparticles up to $80 \mathrm{~nm}$ in size. However, the overall average diameter oscillated between 7 and $28 \mathrm{~nm}$. Larger average sizes were obtained after reaction of silver nitrate with the leaf extracts of mint and marjoram at slow rates of heating. Minimum sizes of $<10 \mathrm{~nm}$ were obtained with basil and peppermint. However, the increase in the heating rate resulted in a statistically significant decrease in the size of the nanoparticles. This fact was more evident in the case of nanoparticles synthesized with marjoram, whose average diameter of $27 \mathrm{~nm}$, obtained at a slow rate of heating, decreased over threefold to $8 \mathrm{~nm}$ at a high rate of heating (see Figs. 1, 2, 3, 4d). 
Fig. 2 Satureja mexicana (mint). a Vis absorption spectra during the reaction time of $10^{-3} \mathrm{M} \mathrm{AgNO}_{3}$ with the plant extract. b Reaction kinetics at different initial heating rates. c Size distribution of the synthesized AgNPs. d AgNP average size after different initial heating rates. $\mathbf{e}, \mathbf{f}$ TEM micrographs
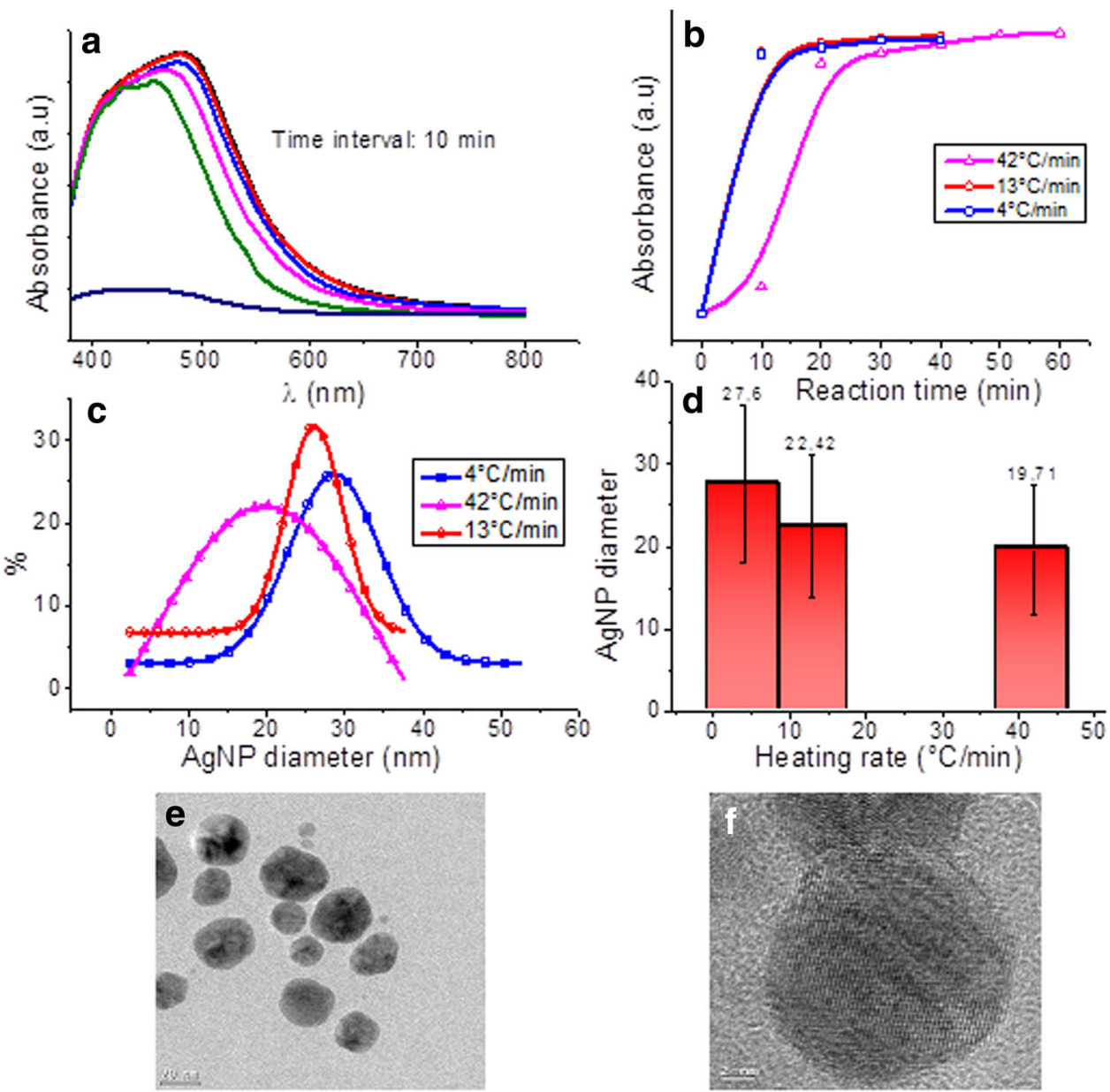

The size distribution for all species and treatments is shown in Figs. 1, 2, 3 and 4c. Generally, speeding up the reaction kinetics via heat tends to sharpen the size distribution curve, except in the case of $S$. mexicana. SEM images of air-dried concentrated emulsions of the obtained AgNPs (Fig. 6) showed that the synthesized nanoparticles have the ability to aggregate in pairs without merging, which make them candidates suitable for the formation of nanoscale functionalized films and other applications. This is also another advantage for AgNPs obtained by the use of plant leaf extracts, which regularly result in AgNPs surrounded by a thin layer of organic matter serving as a capping agent that prevents aggregation and fusion with neighboring nanoparticles.

In addition to narrowing the size distribution, a higher rate of heating produced a smaller size of AgNPs, most likely due to an increased number of precursor growth nuclei and shorter time available for those nuclei to merge with each other. The silver molecules' aggregations are distributed among more numerous growth nuclei, resulting in a larger amount of nanoparticles with shorter average size. Other authors have reported the effects of growing metal nanoparticles at different temperatures (Jiang et al. 2011), but besides this investigation, no work has yet been done in the effect of the initial heating rate. In a similar way, the different dimensions obtained for each species may be useful for the synthesis of certain desired ranges of size. Thus, basil and peppermint are best indicated for the synthesis of particles with an average size between 5 and $15 \mathrm{~nm}$, while marjoram and mint are ideal for a size average between 10 and $25 \mathrm{~nm}$. The average size of AgNPs obtained from plant extracts of other species may be found in the literature (Narayanan and Sakthivel 2011; Gan and Li 2012). Consequently, by considering both the rate of heating and the employed species, the size of the particles may be controlled to obtain an AgNP colloid with certain chosen characteristics.

To develop methods for synthesizing particles of varying shapes and sizes according to the need of the researcher, further parameters may be also considered such as $\mathrm{pH}$, concentration of the foliar extract, and concentration of silver in the solution. This approach has been the topic of much research in different branches of chemistry, since the early 1990s in the search for accurate solutions to 
Fig. 3 Ocimum basilicum (basil). a Vis absorption spectra during the reaction time of $10^{-3} \mathrm{M} \mathrm{AgNO}_{3}$ with the plant extract. b Reaction kinetics at different initial heating rates. c Size distribution of the synthesized AgNPs. d AgNP average size after different initial heating rates. e, f TEM micrographs

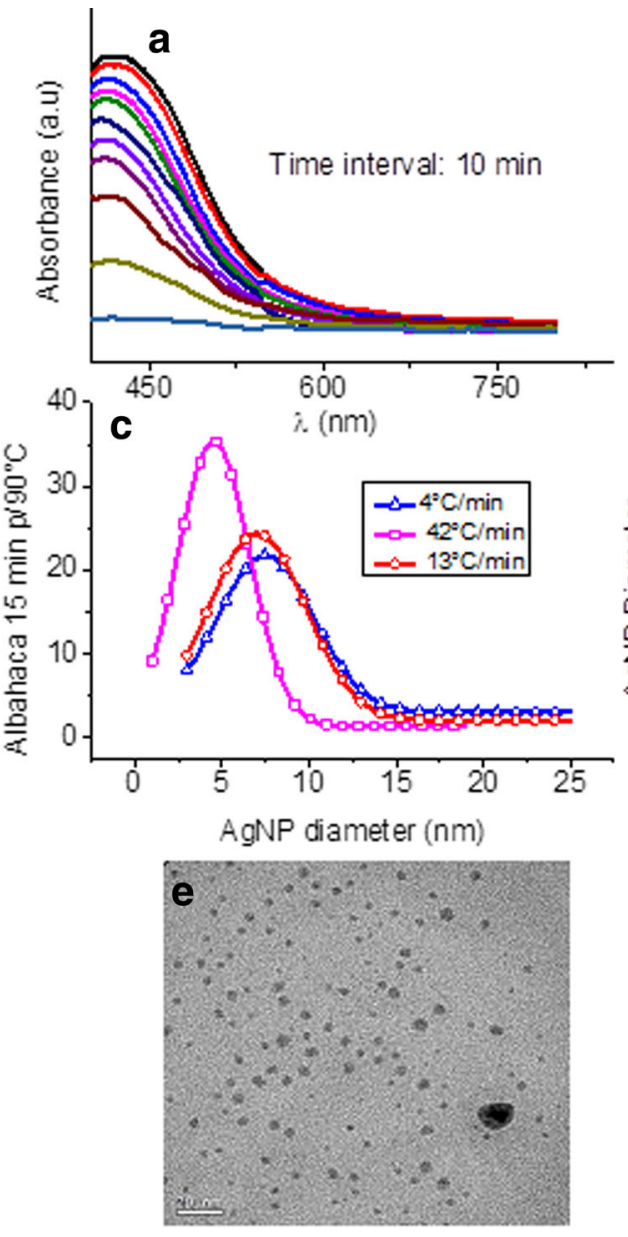

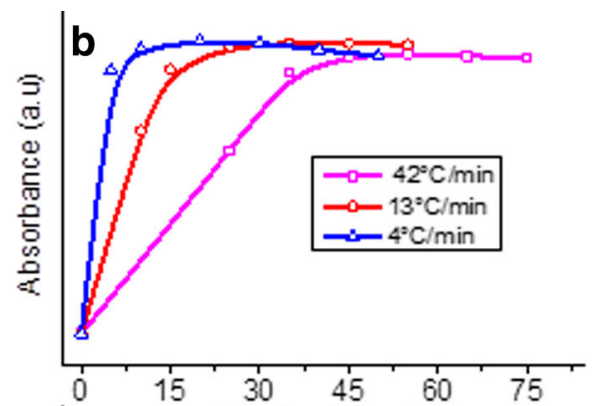

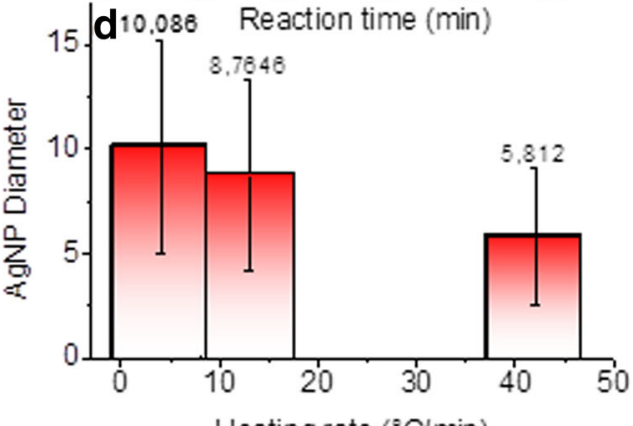

Heating rate $\left({ }^{\circ} \mathrm{C} / \mathrm{min}\right)$

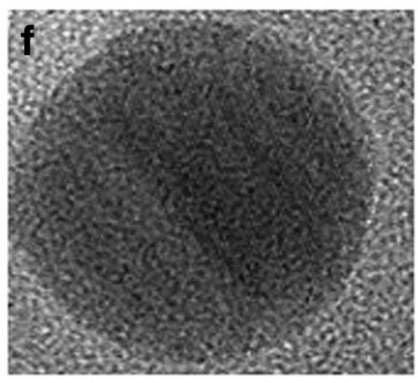

important environmental problems. In accordance with the "green chemistry" movement, the approach focuses on preventing and minimizing waste released into the environment rather than just sensing pollutants and finding ways to eliminate them (Amato 1993).

Physical methods for the synthesis of AgNPs usually employ equipment capable for mass deposition, gas condensation, ionic erosion, laser pulsars, or other solid state reactions. These methods are more expensive than chemical methods, which rely on precipitation, pyrolysis, and other colloidal reactions that require the use of hazardous chemicals (Elechiguerra et al. 2005; Nehl et al. 2006; Zhou et al. 2006). On the contrary, the results in this investigation demonstrate that the synthesis and assembly of metal nanoparticles can be performed through an environmentally friendly process involving the use of natural compounds extracted from vegetables (Bhattacharya and Gupta 2005; Sastry et al. 2004). The use of aqueous plant extracts to control the most relevant physicochemical parameters in the synthesis of AgNPs is a more efficient technique with greater advantages than other techniques using different kinds of biological materials, i.e., bacteria or fungi. This is due in part to the low cost of the plant biomass, low maintenance, and no need for special control or total asepsis. Altogether, we demonstrate a method to control both the size and geometric shape of particles, within a narrow size distribution, giving rise to possible industrial applications that are environmentally friendly.

\section{Conclusions}

The fabrication of metal nanoparticles using aqueous plant extracts is taking importance over traditional methods of synthesis, especially due to their ease of preparation, low cost and low toxicity. Synthesis occurs faster when heat is applied. However, different rates of heating produce AgNPs with different sizes: the higher the rate of heating, the smaller the size of the AgNPs produced. The specific botanical species employed also changes the size of the obtained AgNPs. Thus, a controlled system for the synthesis of any specific range of AgNPs diameter may be designed by combining the use of the selected plant species 
Fig. 4 Mentha piperita

(peppermint). a Vis absorption spectra during the reaction time of $10^{-3} \mathrm{M} \mathrm{AgNO}_{3}$ with the plant extract. b Reaction kinetics at different initial heating rates. c Size distribution of the synthesized AgNPs. d AgNP average size after different initial heating rates. e, f TEM micrographs
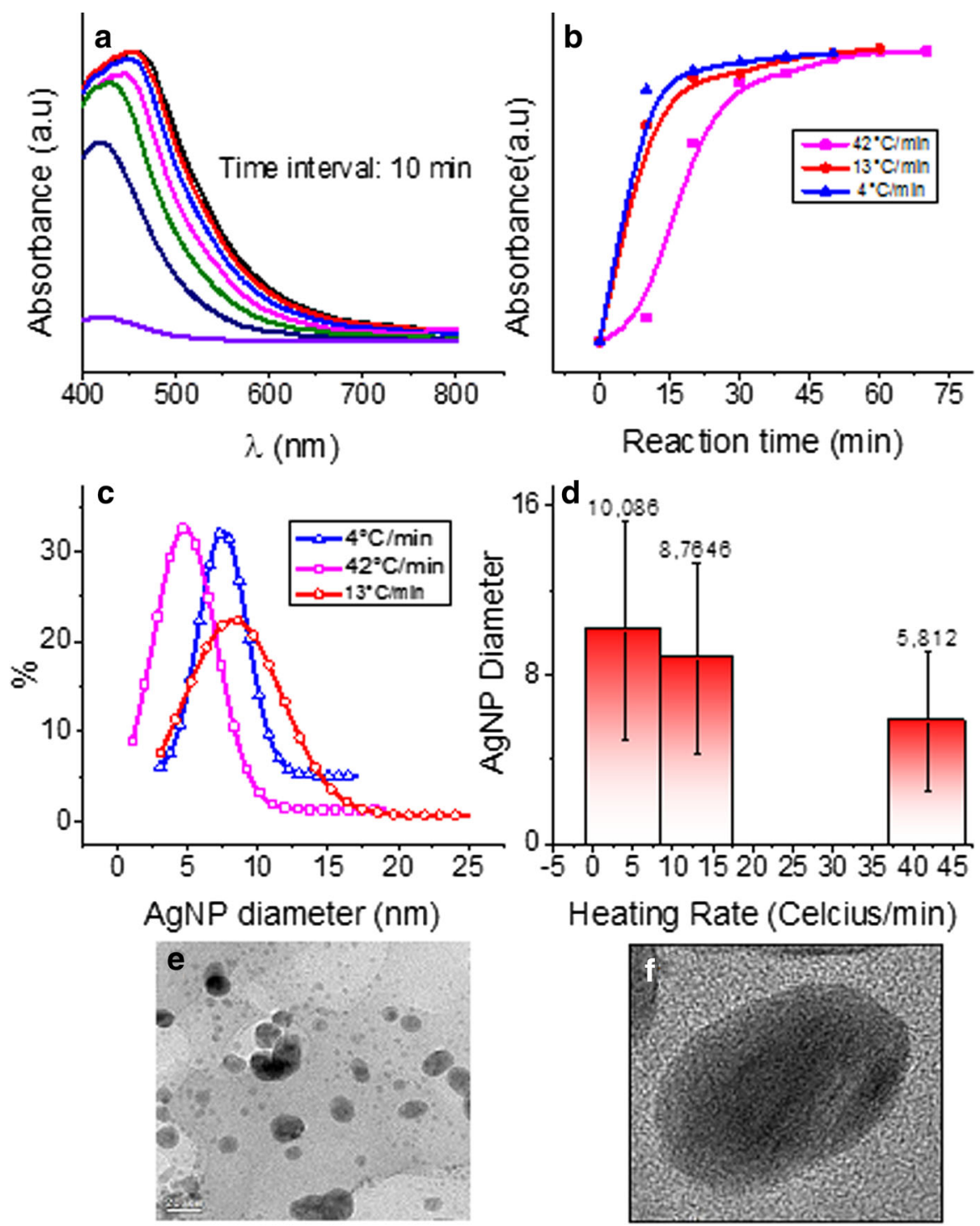

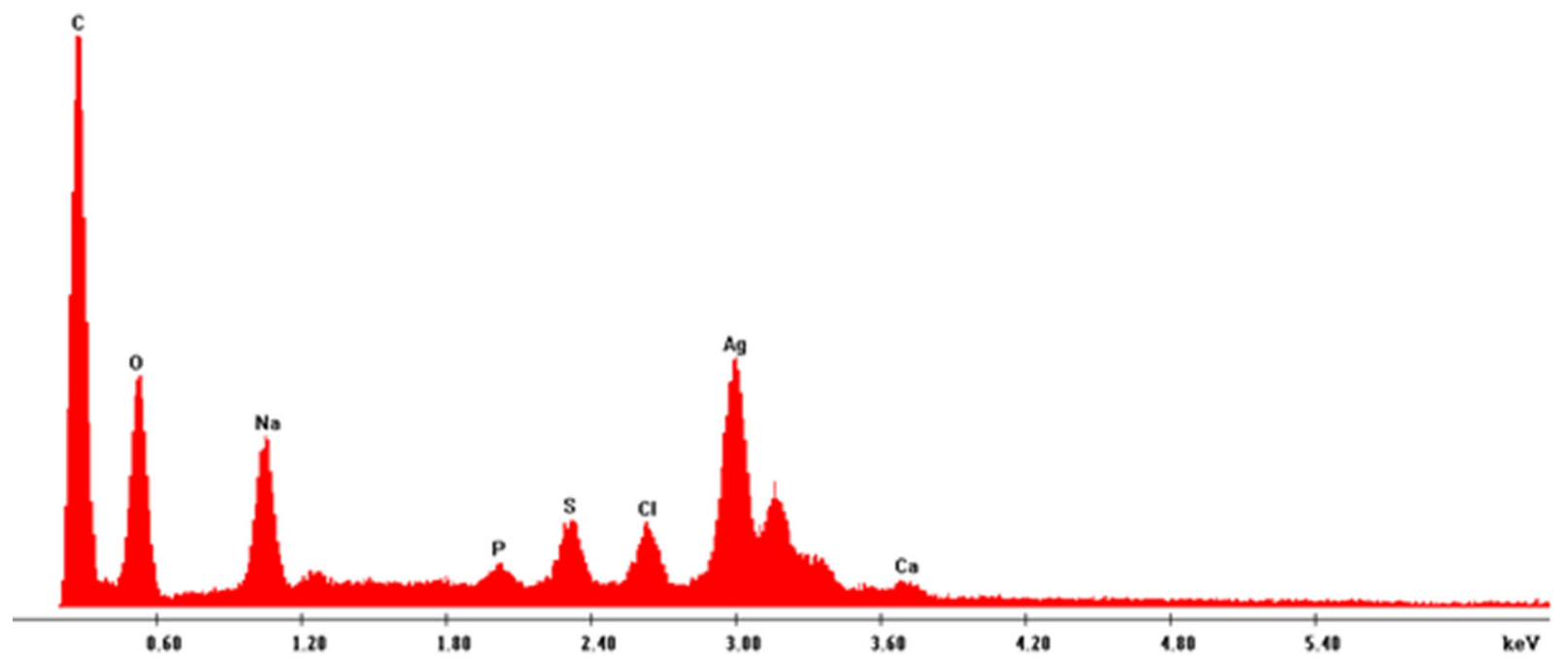

Fig. 5 X-ray elemental microanalysis obtained from a region observed by SEM from a drop of the resulting AgNP emulsion dried over a carbon surface. The most prominent peak corresponds to that of silver. Other elements may come from extract remnants 


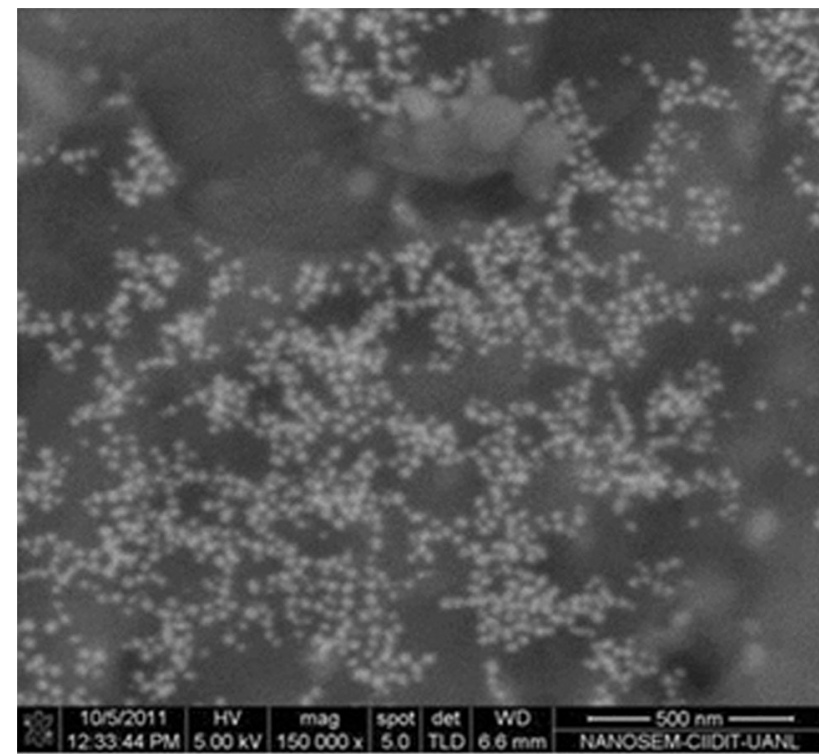

Fig. 6 SEM micrograph from Satureja mexicana. The nanoparticles form closely packed arrangements without merging with each other

and the selected rate of heating to obtain a population of nanoparticles with a desired size.

Acknowledgments This work was funded by SEP-PROMEP and UANL-PAICYT in Mexico.

Open Access This article is distributed under the terms of the Creative Commons Attribution 4.0 International License (http:// creativecommons.org/licenses/by/4.0/), which permits unrestricted use, distribution, and reproduction in any medium, provided you give appropriate credit to the original author(s) and the source, provide a link to the Creative Commons license, and indicate if changes were made.

\section{References}

Ahmad A, Mukherjee P, Senapati S, Mandal D, Khan M, Kumar R, Sastry M (2003) Extracellular biosynthesis of silver nanoparticles using the fungus Fusarium oxysporum. Colloids Surf B Biointerfaces 28:313-318

Amato I (1993) The slow birth of green chemistry. Science 259:1538-1541

Anastas PT, Warner JC (1998) Green chemistry: theory and practice. Oxford University, New York, p 30

Bailey LH (1949) Manual of cultivated plants most commonly grown in the continental United States and Canada. Macmillan, New York, pp 847-865

Bhattacharya D, Gupta RK (2005) Nanotechnology and potential of microorganisms. Crit Rev Biotechnol 25:199-204

Boisselier E, Astruc D (2009) Gold nanoparticles in nanomedicine: preparations, imaging, diagnostics, therapies and toxicity. Chem Soc Rev 38:1759-1782

Chan WCW (2006) Bionanotechnology progress and advances. Biol Blood Marrow Transplant 12:87-91

Elechiguerra JL, Burt JL, Morones JR, Camacho-Bragado A, Gao X, Lara H, Yacaman MJJ (2005) Interaction of silver nanoparticles with HIV-1. J Nanobiotechnol 3(6):1-10
Epling C, Játiva C (1966) A descriptive key to the species of Satureja indigenous to North America. Brittonia 18:244-248

Fayaz AM, Balaji K, Kalaichelvan PT, Venkatesan R (2009) Fungal based synthesis of silver nanoparticles - an effect of temperature on the size of particles. Colloids Surf B Biointerfaces 74:123-126

Gan PP, Li SFY (2012) Potential of plant as a biological factory to synthesize gold and silver nanoparticles and their applications. Rev Environ Sci Bio-Technol 11:169-206

Gardea JL, Gomez E, Peralta J, Parsons J, Troiani H, Yacaman MJ (2003) Alfalfa sprouts: a natural source for the synthesis of silver nanoparticles. Langmuir 19:1357-1361

Glasauer A, Chandel NS (2013) ROS. Curr Biol 23:100-102

Glomm RW (2005) Functionalized nanoparticles for application in biotechnology. Dispers Sci Technol 26:389-414

Iravani S (2011) Green synthesis of metal nanoparticles using plants. Green Chem 13:2638-2650

Jiang XC, Chen WM, Chen CY, Xiong SX, Yu AB (2011) Role of temperature in the growth of Silver nanoparticles through a synergetic reduction approach. Nanoscale Res Lett 6:32

Lee SJ, Umano K, Shibamoto T, Lee KG (2005) Identification of volatile components in basil (Ocimum basilicum L.) and thyme leaves (Thymus vulgaris L.) and their antioxidant properties. Food Chem 91:131-137

Lubbe A, Verpoorte R (2011) Cultivation of medicinal and aromatic plants for specialty industrial materials. Ind Crops Prod 34:785-801

Mittal AK, Chisti Y, Banerjee UC (2013) Synthesis of metallic nanoparticles using plant extracts. Biotechnol Adv 31:346-356

Narayanan KB, Sakthivel N (2011) Extracellular synthesis of silver nanoparticles using the leaf extract of Coleus amboinicus Lour. Mater Res Bull 46:1708-1713

Nehl CL, Liao HW, Hafner JH (2006) Optical properties of starshaped gold nanoparticles. Nano Lett 6:683-688

Sastry M, Ahmad A, Khan MI, Kumar R (2004) Microbial nanoparticle production. In: Niemeyer CM, Mirkin CA (eds) Nanobiotechnology. Wiley-VCH, Weinheim, pp 126-135

Sukdeb P, Tak YK, Song JM (2007) Does the antibacterial activity of silver nanoparticles depend on the shape of the nanoparticle? A study of the gram-negative bacterium Escherichia coli. Appl Environ Microbiol 6:1712-1720

Suresh S, Venkitaraj KP, Selvakumar P, Chandrasekar M (2011) Synthesis of $\mathrm{Al}_{2} \mathrm{O}_{3} \mathrm{Cu}$ /water hybrid nanofluids using two step method and its thermo physical properties. Colloids Surf A Physicochem Eng Asp 388:41-48

Takabi B, Salehi S (2014) Augmentation of the heat transfer performance of a sinusoidal corrugated enclosure by employing hybrid nanofluid. Adv Mech Eng 6:147059

Takabi B, Shokouhmand $\mathrm{H}$ (2015) Effects of $\mathrm{Al}_{2} \mathrm{O}_{3}-\mathrm{Cu} /$ water hybrid nanofluid on heat transfer and flow characteristics in turbulent regime. Int J Mod Phys C 26:1550047

Triantaphylide C, Havaux M (2009) Singlet oxygen in plants: production, detoxification and signaling. Trends Plant Sci $14: 219-228$

Vági E, Rapavi E, Hadolin M, Perédi K, Baláz A, Blázovics A, Simándi B (2005) Phenolic and triterpenoid antioxidants from Origanum majorana $\mathrm{L}$. herb and extracts obtained with different solvents. J Agric Food Chem 53:17-21

Zar JH (2010) Biostatistical analysis, 5th edn. Prentice-Hall, New Jersey, p 947

Zhou WP, Lewera A, Larsen R, Masel RI, Bagus PS, Wieckowski A (2006) Size effects in electronic and catalytic properties of unsupported palladium nanoparticles in electrooxidation of formic acid. J Phys Chem B 110:13393

Zygmunt S (2010) Biosynthesis and application of silver and gold nanoparticles. In: Perez DP (ed) Silver nanoparticles. INTECH, pp 257-272 